$\mathbb{P}$ periodica polytechnica

Civil Engineering

$54 / 2(2010) 101+106$

doi: 10.3311/pp.ci.2010-2.05

web: http://www.pp.bme.hu/ci

(c) Periodica Polytechnica 2010

RESEARCH ARTICLE

\section{A simulation-optimisation methodology for designing the operation of emergency reservoirs in the Hungarian Tisza basin}

László Koncsos / Edina Balogh

Received 2009-09-10, revised 2009-11-30, accepted 2010-03-08

\begin{abstract}
This work reports the results of an investigation of reservoirs that were selected in Hungary in the framework of a new flood control strategy for the River Tisza, the largest tributary of the River Danube. Through a comprehensive analysis the optimal operation mode was identified, which would need to be applied to achieve the maximum decreasing effect on peak water levels. The flood waves were simulated using a $1 D$ hydrodynamical model, which is based on the Saint-Venant equations. Both measured and synthetic discharge data were used as boundary conditions. The time lead as compared to the flood peak was determined for the reservoir system. On the Upper-Tisza the figures exceed the order of magnitude of the possible time lead of the realistic forecast, meaning that further research of the reconditioned discharge forecast is necessary. The investigation results of the interaction of two reservoirs showed that the sum of the decreasing effects on water levels when separated reservoirs work independently approaches the decreasing effect of the jointly operating reservoirs reasonably well. Therefore the joint impacts can be estimated using quick linear programming methods.
\end{abstract}

\section{Keywords}

flood control $\cdot$ reservoir systems $\cdot 1 D$ hydrodynamic model

\section{Acknowledgement}

This work is connected to the scientific program of the "Development of quality-oriented and harmonized $R+D+I$ strategy and functional model at BME" project. This project is supported by the New Hungary Development Plan (Project ID: TÁMOP4.2.1/B-09/1/KMR-2010-0002).

\section{László Koncsos}

Department of Sanitary and Environmental Engineering, BME, H-1111 Budapest, Múegyetem rkp. 3., Hungary

e-mail:koncsos@vkkt.bme.hu

\section{Edina Balogh}

Hungarian Academy of Sciences, Water Resources Research Team, H-1111 Budapest, Múegyetem rkp. 3., Hungary

e-mail: edina@vkkt.bme.hu

\section{Introduction}

The River Tisza (Fig. 1) is the longest tributary of the River Danube. It flows through five countries - Ukraine, Hungary, Slovakia, Romania, and Serbia - and its catchment area, one of the most important regions in the Danube River Basin, is $157,000 \mathrm{~km}^{2}$.

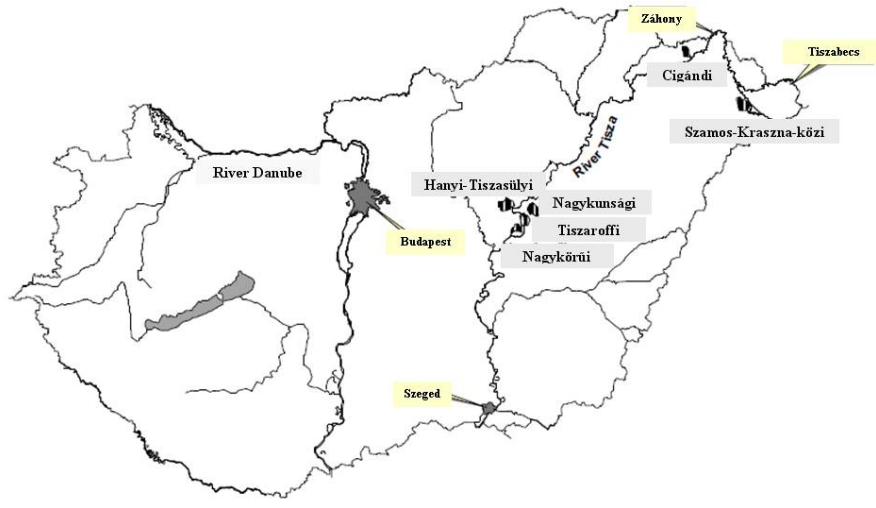

Fig. 1. Location of the reservoirs and the upstream/downstream borders of the study area

The mean discharge at Szeged (in the downstream Hungarian boundary section) is $820 \mathrm{~m}^{3} / \mathrm{s}$, the largest discharge in case of floods has been $3550 \mathrm{~m}^{3} / \mathrm{s}$ so far. Considerable floods occur every 5-6 years on average, whose duration is 15 to 120 days in the downstream reach of the river [11]. In flood events water levels can rise even $6 \mathrm{~m}$ during 24 to 36 hours on the Upper-Tisza.

After a relatively dry period of more than one decade, in the last few years unexpected floods of the River Tisza (especially the flood in March 2001, which resulted in a dike failure) have drawn attention to the problem of rising of flood peak water levels. This symptom can be attributed to changes of the floodplain, to climate change and, of course, to the construction of dykes. These rising flood water levels neccesitated the revision and further development of the Hungarian flood control system. Having identified the problem, a novel flood control plan was developed. This includes the building of the existing dike system to the prescribed level (protection ability of the existing flood dikes was analysed e.g. in [10]), as well as new solutions, such 
as regulating the outflow at emergency reservoirs or improving conveyance conditions on the floodplain. In response, the idea of regulated outflow at reservoirs appeared as a new element of the flood control strategy. Six emergency reservoirs (Fig. 1) were to be built in the first stage of this plan in accordance with the government measure of 2003. The volumetric capacity of the planned reservoirs will be $85-302$ million $\mathrm{m}^{3}$ each, while the total volume of the system is expected to be 850 million $\mathrm{m}^{3}$. The basic data of the six reservoirs are shown in Table 1

Tab. 1. Reservoir data

\begin{tabular}{cccc}
\hline Reservoir name & $\begin{array}{c}\text { Location } \\
{[\mathrm{rkm}]^{*}}\end{array}$ & $\begin{array}{c}\text { Sluice capacity } \\
{\left[\mathrm{m}^{3} / \mathrm{s}\right]}\end{array}$ & $\begin{array}{c}\text { Volumetric capacity } \\
{\left[\text { million }{ }^{3}\right]}\end{array}$ \\
\hline Szamos-Kraszna-közi & 690 & 660 & 121 \\
\hline Cigándi & 597 & 160 & 85 \\
\hline Nagykunsági & 404 & 80 & 100 \\
\hline Hanyi-Tiszasülyi & 387 & 250 & 302 \\
\hline Tiszaroffi & 370 & 100 & 93 \\
\hline Nagykörüi & 355 & 150 & 149 \\
\hline
\end{tabular}

*distance from the mouth of the river

The maximum level of flood waves can be reduced through utilising the reservoirs. It is an essential and at the first sight complicated task to determine the optimum operation strategy (i.e. identifying when the magnitude and the expansion of the actual decreasing effect are at their maximum). The simultaneous operation of a group of reservoirs influences the optimal operation strategy. To simplify the solution of this problem, the following question must be answered: can the decreasing effect on water levels be superposed to each other if more reservoirs are operated separately?

The purpose of the present paper is to find the individual optimum strategy concerning the six selected reservoirs, moreover, to investigate the simultaneous operation of a group of reservoirs, on the example of a dual reservoir system.

\section{Methodology}

\subsection{Objective function}

The impacts of the reservoir system on flood levels can be described with several functions. Based on detailed analysis we have selected the function which measures the effects of reservoirs on decreasing the maximum water levels during a given flood wave:

$$
H=\int_{x=x 1}^{x=x^{2}} \Delta z(x) d x=\int_{x=x 1}^{x=x_{2}}\left(Z_{0 \max (x)}-Z_{T \max (x)}\right) d x
$$

where $Z_{0 \max (x)}$ is the longitudinal envelope profile of the maximum levels of flood waves without implementing the planned reservoirs; $Z_{T \max (x)}$ is the longitudinal profile of the maximum levels of flood waves if the operation of the planned reservoirs is taken into consideration, and $x 1$ and $x 2$ are the upstream and the downstream boundary coordinates of the investigated reach (Fig. 1), respectively.

The reservoir system works in an optimal way if the decrease in the water level, which is measured by the selected objective function, is at a maximum - taking into account all possible operating strategies. The optimal reservoir operation is assumed as follows: within any $j \cdot \Delta t-(j+1) \cdot \Delta t(j=1, \ldots, n)$ period of time, there is a $q_{j}$ steady-state flux withdrawn to the reservoir in a controlled way. If the $\Delta t$ period is appropriately short, even complicated discharge hydrographs can be sufficiently approximated by this discrete time series. Assuming the operation of a group of reservoirs, which includes $m$ number of reservoirs, we have to optimize the following elements:

$$
q_{j}^{i}(i=1, \ldots, m)(j=1, \ldots, n),
$$

where $i=1 \ldots m$ is the number of reservoirs and $j=1 \ldots n$ is the number of time steps.

The objective function representing the reduction of water levels as a consequence of the reservoir operation depends on the $q_{j}^{i}$ elements.

The character of the dependence is unknown, but it can be calculated using the Saint-Venant equations.

We have to find the $q_{j}^{i}$ elements which reaches the maximum of the (Eq.2) objective function of optimisation.

$$
H=f\left(q_{j}^{i}(i=1, \ldots, m)(j=1, \ldots, n)\right) .
$$

The search for the optimum of $H$ is subjected to constraints, namely that the amount of the withdrawn water is less than the $V_{i}$ available storage capacity of any of the reservoirs, thus:

$$
\sum_{j=1}^{n} q_{j}^{i} * \Delta t \leq V_{i}
$$

\subsection{D hydrodynamic mode}

For the purpose of calculating the effect of reservoirs a conventional 1D unsteady hydrodynamic model was used based on the solution of the Saint-Venant equations of mass and momentum conservation (Eq. 3 4.

$$
\begin{gathered}
\frac{\partial Q}{\partial x}+\frac{\partial A}{\partial t}-q=0, \\
\frac{\partial z}{\partial x}+\frac{\alpha^{\prime} Q^{2}}{g A^{3}} \frac{\partial A}{\partial x}-\frac{\alpha^{\prime}, Q}{g A^{2}} \frac{\partial A}{\partial t}+\frac{\alpha^{\prime} Q}{g A^{2}} \frac{\partial Q}{\partial x} \\
+\frac{\alpha,}{g A} \frac{\partial Q}{\partial t}+\frac{Q^{2}}{K^{2}}+\frac{\alpha^{\prime \prime} Q q}{g A^{2}}=0,
\end{gathered}
$$

where $x=$ abscissa in streamwise direction; $t=$ time; $Q=$ discharge; $z=$ free surface elevation; $A=$ wetted cross-sectional area; $q=$ lateral discharge per unit length $\left[\mathrm{m}^{3} / \mathrm{s} / \mathrm{m}\right]=\left[\mathrm{m}^{2} / \mathrm{s}\right] ; g=$ acceleration of gravity; $\alpha^{\prime}$, $\alpha^{\prime \prime}=$ dispersion coefficient of the momentum and the local acceleration; $K=A c \sqrt{R}=$ conveyance coefficient per unit length ( $c=$ velocity coefficient; $R=$ hydraulic radius). 
The solution of the Saint-Venant equations was performed with an implicit method of finite differences. The resulting nonlinear system of equations is solved by using the ,doublesweep" method (see e.g. [1]; [9]).

In the course of the simulation discharge hydrograph was used as upstream boundary condition and a fixed water level or rating curve as downstream boundary condition. The model makes it possible to simulate tributaries, reservoirs or dike breaches as linear inflows or outflows, as is represented in Eq. (3.4). In the present case there is an outflow from the river filling up the reservoir.

To simplify model calibration the river was divided into characteristic reaches. The calculation was based on the principle that the model should be calibrated with the minimum number of physical parameters. That is why only two Manning-coefficients were attributed for each reach representing roughness conditions in the main channel and in the floodplain, respectively. Both parameters were presumed to be independent on water depth. The parameter estimation was carried out with the purpose to minimize the square sum of the differences between measured and calculated water levels.

Fig. 2 presents the calculated and measured water levels at Záhony (Fig. 1) for a complete year. In most cases, the model follows the changes of water levels around the highest peaks in an acceptable way as shown in Fig. 2 .

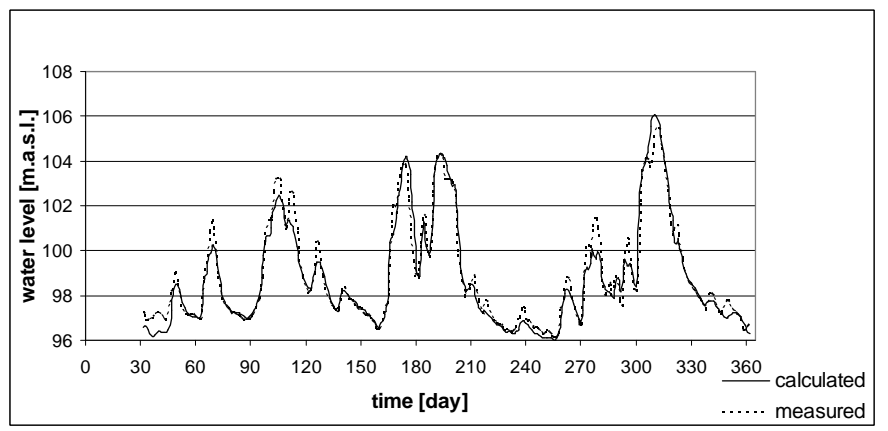

Fig. 2. Modelled water level time series at Záhony, prescribing upstream discharge boundary condition at Tiszabecs (Fig. 1) and downstream water level boundary condition at Tokaj

\subsection{Optimisation}

Numerous optimisation models can be applied for engineering problems (see e.g. [7] and [8]). To find the optimal operation scheme of a reservoir system there are several optimisation scheme too (see e.g. [5] and [6]). In this work the following optimisation algorithm was used: the optimisation was carried out with the BLIND stochastic adaptive algorithm [4], which combines the advantages of the Monte Carlo methods and the classic convergent search algorithms. The procedure starts from the initial range of parameter values and gradually searches the minimum of the parameter range in the subspaces of the ordered sample, generating random parameter combinations, assisted by extreme value statistics.
The optimized parameters were the withdrawal discharges, assumed to be constant during 24-hour periods. The initial range of parameters was determined between zero and the maximum withdrawal capacity, where the maximum withdrawal is the sluice capacity of the given reservoir (see Table 1).

The storage capacity (see Table 1) was a limiting condition in the process of optimising reservoir operation. Those cases which resulted in a water storage quantity larger than the reservoir volumetric limitation, were filtered out using a penalty function: increasing the actual value of the efficiency function by the amount of withdrawn water leads to storage capacity moving away from the minimum value.

\subsection{Storage function}

In the course of the simulation, the current water level in the reservoir was calculated in every stage as a function of the $q_{j}^{i}$ elements. There was a withdrawal if the water level of the river at the reservoir section was higher than the water level in the reservoir.

The water level in the reservoir was calculated based on the storage function (Eq. 5) which describes the storage curve (see Fig. 3).

$$
z=z_{\min }+\sqrt{\frac{V}{\beta}}
$$

where $z=$ water level in the reservoir; $z_{\min }=$ reservoir bottom level; $V=$ water storage quantity; $\beta=$ storage coefficient.

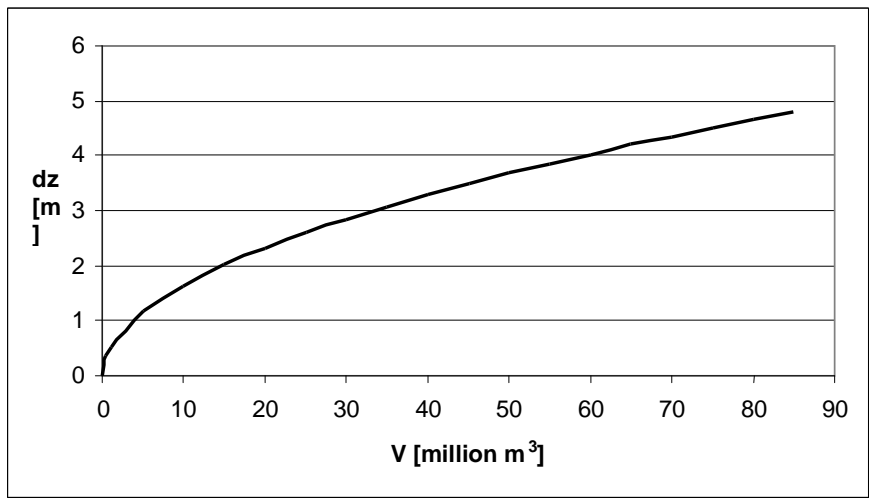

Fig. 3. Storage curve of the Cigándi reservoir $\left(\mathrm{dz}=\mathrm{z}-\mathrm{z}_{\min }\right)$

Reservoir storage data are shown in Table 2

\section{Results}

The research work focused on analysing the effect of the six reservoirs to be built in the first stage of the new flood control plan. These are the Szamos-Kraszna-közi, Cigándi, HanyiTiszasülyi, Nagykörüi, Nagykunsági and Tiszaroffi reservoirs, as seen in Fig. 1 .

As boundary conditions both measured and numerically generated data were used. Simulated flood waves were produced using a synthetic generator reflecting the statistical features of the tributaries' regimes [3]. For determining the parameters of 
Tab. 2. Storage data

\begin{tabular}{ccc}
\hline Reservoir name & $\begin{array}{c}\text { Bottom level } \\
\text { [m.a.s.l.] }\end{array}$ & $\begin{array}{c}\text { Storage } \\
\text { coefficient }\end{array}$ \\
\hline Szamos-Kraszna & 109 & 8.8 \\
\hline Cigánd & 94 & 3.7 \\
\hline Nagykunsági & 85 & 7.4 \\
\hline Hanyi-Tiszasülyi & 85 & 17.7 \\
\hline Tiszaroff & 83 & 2.2 \\
\hline Nagykörü & 83 & 5.3 \\
\hline
\end{tabular}

the synthetic generator, discharge time series from 1984-2003 were used.

The tributaries (Szamos, Kraszna, Bodrog, Sajó, Hernád, Körös, and Maros) were considered as lateral discharges, using generated discharge hydrographs. These tributaries are shown in Fig. 4.

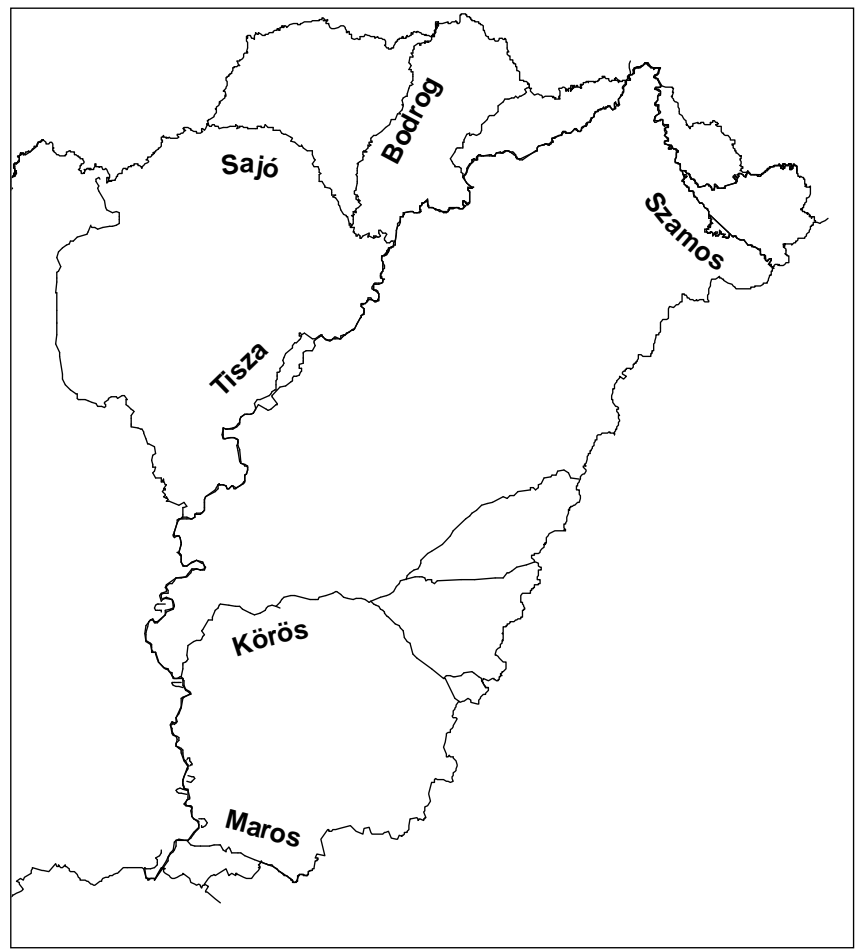

Fig. 4. Location of the tributaries

Extreme discharge combinations in the upstream boundary sections of the tributaries which have not been detected until now but are possible according to statistical probability can be also produced by the generator. Using water level and discharge data of several decades at the boundaries, an autoregressive moving average model was developed [2] for each tributary. The statistical model calculated discharges in daily time steps, accounting for discharge cross-correlations between the tributaries. Fast flood routing methods were then used to simulate water level time series on the Tisza with the discharge boundary conditions produced by the synthetic discharge generator. This method ensured the handling of flow computation along the tributaries without direct consideration of geometric data. The main feature of this method is that the flood wave propagates from the upstream boundary section to the mouth of the tributaries determined by a linear model of reservoir series using two parameters, known also as cascade model (the parameters of which having been previously calibrated with real flood waves). At the confluences the flood waves appear as lateral boundary conditions of the hydrodynamical model based on Eq. 3.4.

The number and the timing of the withdrawal intervals were determined depending on the sluice capacity of the reservoirs and the development of the flood wave at the reservoir sections. It was assumed, that the sluices are capable to meet the withdrawal capacity resulted from the optimalisation.

The optimisation results (see Figs. 5-10) show that the withdrawal concentrates mainly on the rising phase of the flood wave when the reservoir needs to be filled to maximum capacity. Before and after that time the necessary withdrawal capacity decreases quickly.

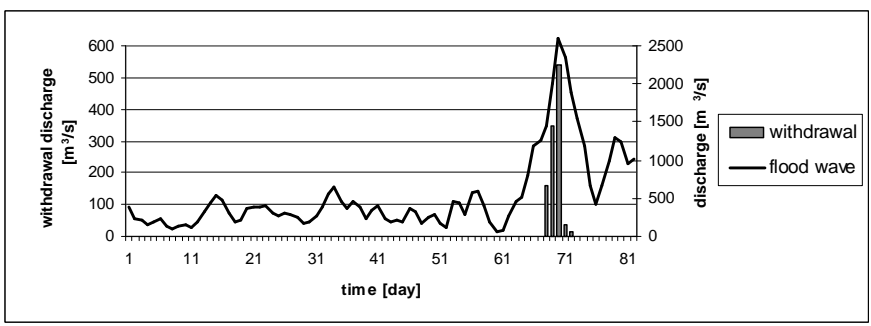

Fig. 5. Optimum withdrawals compared to the flood wave (SzamosKraszna-közi reservoir)

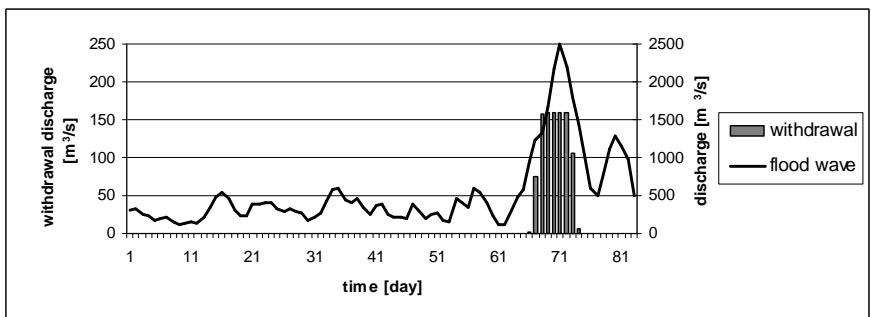

Fig. 6. Optimum withdrawals compared to the flood wave (Cigándi reservoir)

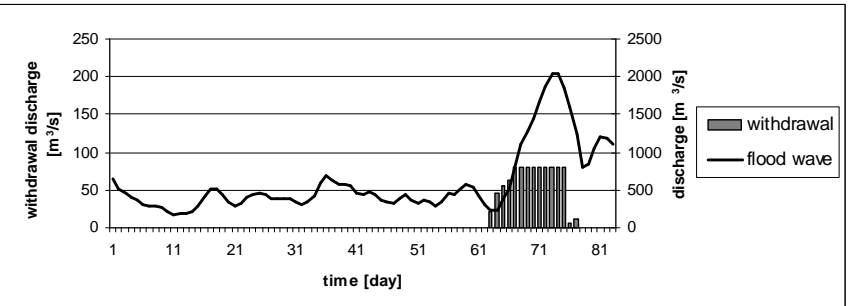

Fig. 7. Optimum withdrawals compared to the flood wave (Nagykunsági reservoir) 


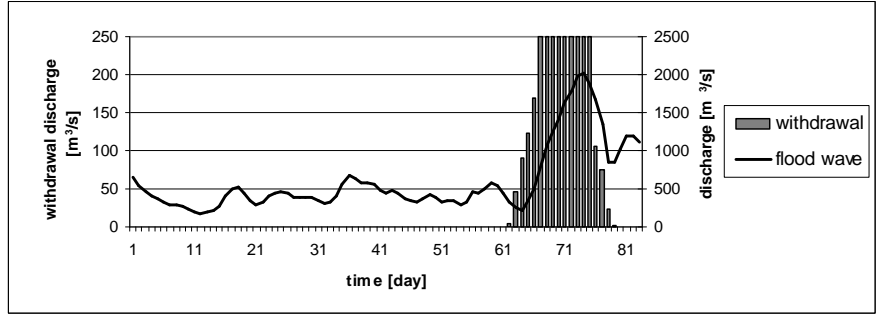

Fig. 8. Optimum withdrawals compared to the flood wave (Hanyi-Tiszasülyi reservoir)

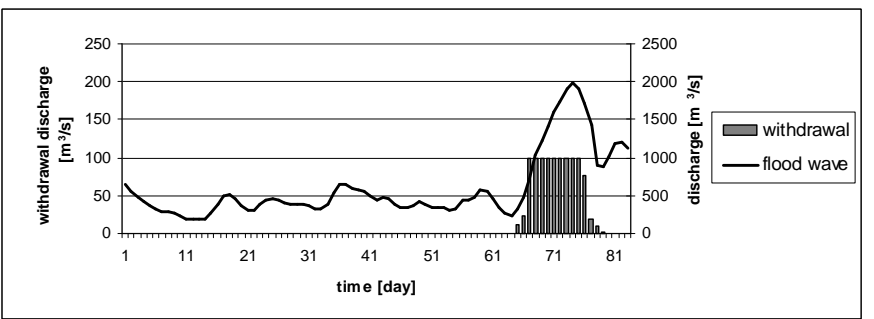

Fig. 9. Optimum withdrawals compared to the flood wave (Tiszaroffi reservoir)

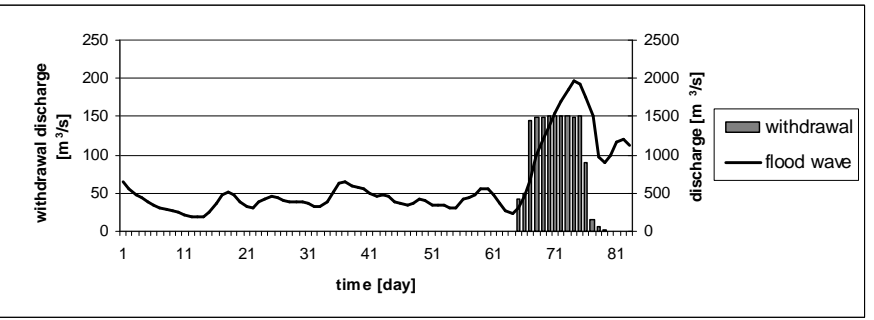

Fig. 10. Optimum withdrawals compared to the flood wave (Nagykörüi reservoir)
These characteristics of reservoir operation underline the need for reliable flood forecasting for flood waves along the entire Tisza. The time interval between the initial phase of operations and the flood peak is variable: it is up to 2 days at the Szamos-Kraszna-közi reservoir, 4 days at the Cigándi reservoir, but it can reach, or even exceed, 10 days in the case of the other reservoirs. These data correspond to the order of magnitude of a realistic forecast - mainly on the Middle-Tisza. On the UpperTisza the data exceed this order of magnitude, so in the future new discharge forecasts, based on the forecast of the meteorological factors, need to be developed and implemented.

The analysis of the simultaneous operation of a group of reservoirs was performed with two operating reservoirs: the Tiszaroffi reservoir at the middle section of the study reach and the Cigándi reservoir on the Upper-Tisza. For both reservoirs 12 half a day intervals were assumed with constant discharge, so 24 parameters needed to be optimized.

In order to analyze the reservoir interaction, a "standard" flood wave (Fig. 11) was constructed as an upstream boundary condition. The "standard" flood wave is particularly simplified, nevertheless suitable to investigate the interaction of reservoirs, as it is shown later. It was created according to discharge data for Tiszabecs from 1993 to 2003. The procedure was the following: flood waves with discharge values higher than $1200 \mathrm{~m}^{3} / \mathrm{s}$ were selected (according to a detailed analysis above this value a statistically representative number of flood waves can be found), in a time window 4 days both before and after the flood peak. These flood waves were averaged after normalizing. The downstream boundary condition was a fixed water level.

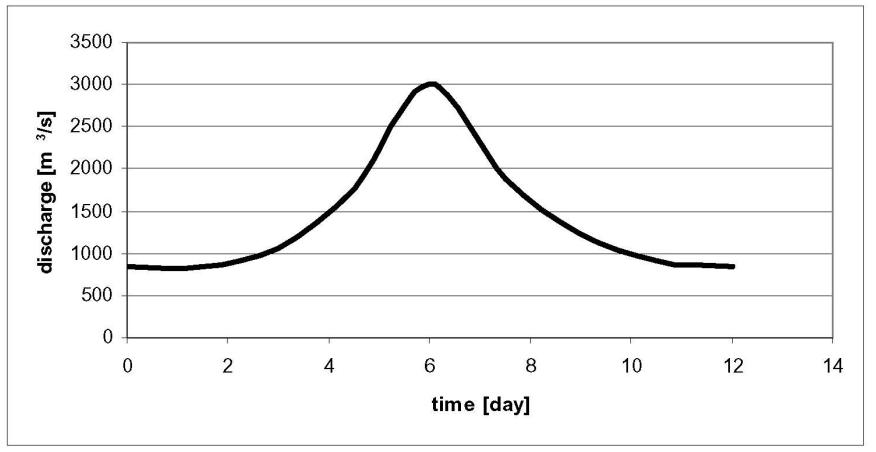

Fig. 11. „Standard” flood wave

The results show that the sum of the decreasing effects on the water level calculated with the optimal strategy of individual reservoirs coincides well with the computed values assuming joint operation of the two reservoirs (Fig. 12). Thus, it is enough to model the operation of the reservoirs separately from each other; the joint impacts can be calculated for example with the methods of linear programming, resulting in a much quicker solution than the applied optimisation algorithm with many parameters. The speed of calculation is an important factor in the real-time application of the model (e.g. during a flood). 


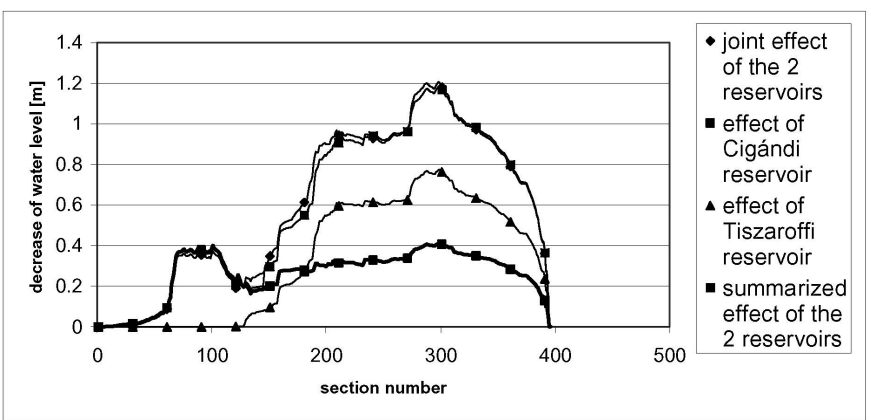

Fig. 12. Joint and summarized impacts of two reservoirs

\section{Conclusions}

The optimal operation scheme of the reservoirs which are planned to improve the flood control system on the River Tisza was investigated using an 1D hydrodynamic model. Identification of the optimum operation strategy was carried out using the BLIND stochastic adaptive algorithm.

Based on the investigations, the following conclusions can be drawn:

1 The withdrawal period should concentrate mainly on the rising phase of flood waves for all reservoirs. During these periods the reservoirs need to be filled to maximum capacity.

2 The time lead necessary in relation to the flood peak, exceeds the possible time lead of the accurate forecast on the UpperTisza, which points to the necessity of providing discharge forecast on a new basis in the future. On the Middle-Tisza there is no such a problem.

3 According to the numerical analysis related to reservoir interaction, the sum of the decreasing effects on water level calculated with the optimal strategy of individual reservoirs coincided well with the computation assuming the joint operation of the two reservoirs. Therefore the joint impacts can be calculated with linear programming methods, which provides an essentially quicker solution than a non-linear algorithm.

The results summarized in this paper were used during the planning of the reservoirs, out of which the construction of two reservoirs has already begun.

\section{References}

1 Abbott M B, Computational hydraulics - elements of the theory of free surface flows, Pitman, London, UK, 1979.

2 Box G E P, Jenkins G M, Time series analysis, Holden-Day, San Francisco, California, USA, 1970.

3 Koncsos L, Flood control of river Tisza in the Carpathian basin, Budapest University of Technology and Economics Department of Sanitary and Environmental Engineering, Budapest, Hungary, 2006. in Hungarian.

4 Koncsos L, Schütz E, Windau U, Application of a comprehensive decision support system for the water quality management of the river Ruhr, Germany, Modelling and management of sustainable basin-scale water resource systems, 1995.

5 Labadie $\mathbf{J} \mathbf{W}$, Reservoir system optimization models, Water Resources Update Journal 108 (1997), 83-110.
6 , Optimal operation of multireservoir systems: state-of-the-art review, Journal of Water Resources Planning and Management 130 (2004), no. 2, 93111, DOI 10.1061/(ASCE)0733-9496(2004)130:2(93).

7 Lógó J, Ghaemi M, Vásárhelyi A, Stochastic Compliance Constrained Topology Optimization Based On Optimality Criteria Method, Periodica Polytechnica Civil Engineering 51 (2007), no. 2, 5-10, DOI 10.3311/pp.ci.2007-2.02.

8 Lógó $\mathbf{J}$, New type of optimality criteria method in case of probabilistic loading conditions, Mechanics Based Design of Structures and Machines 35 (2007), no. 2, 147-162, DOI 10.1080/15397730701243066.

9 Mahmood K, Yevjevich V, Unsteady flow in open channels, Water Resources Publications, Littleton, CO, USA, 1975.

10 Nagy L, Hydraulic failure probability of a dike cross section, Periodica Polytechnica Civil Engineering 52 (2008), no. 2, 83-89, DOI 10.3311/pp.ci.20082.04 .

11 Somlyódy L, Strategic colums of the national water management, Strategic issues of the national water management, 2000, pp. 35-82. In Hungarian. 